\title{
PENGARUH ASAM HUMAT DAN PEMUPUKAN P TERHADAP RESPIRASI TANAH PADA PERTANAMAN JAGUNG DI TANAH ULTISOLS
}

\section{EFFECT OF HUMIC ACID AND PHOSPHATE FERTILIZATION ON THE SOIL RESPIRATION OF CORN PLANTS ON ULTISOLS}

\author{
Andri Lukmansyah*, Ainin Niswati, Henrie Buchari, dan Abdul Kadir Salam \\ Jurusan Agroteknologi Fakultas Pertanian Universitas Lampung \\ Jalan Prof. Dr. soemantri Brojonegoro No.1 Bandar Lampung 35145 \\ *E-mail: andri.lukmansyah95@gmail.com
}

\begin{abstract}
Ultisols is one type of soil that has soil acidity problems, organic matter and P availability. Efforts to improve the quality of Ultisols soils are by applying the use of $P$ fertilizer with soil conditioner. The research aims to study the effect of humic acid and $P$ fertilization on soil respiration. This research was carried out from December 2018 to May 2019 in the Agricultural Technology Assessment Agency (BPTP) Natar, using a factorial randomized block design with two treatment factors. The first factor is without humic acid (H0), humic acid $15 \mathrm{~kg} \mathrm{ha-1} \mathrm{(H1)} \mathrm{and} \mathrm{humic} \mathrm{acid} 30 \mathrm{~kg} \mathrm{ha-1}$ (H2). The second factor is without TSP fertilizer (P0), TSP fertilizer $100 \mathrm{~kg} \mathrm{ha-1} \mathrm{(P1),} \mathrm{TSP} \mathrm{fertilizer} 200 \mathrm{~kg}$ ha-1 (P2) and TSP fertilizer $300 \mathrm{~kg} \mathrm{ha-1}$ (P3). The data obtained were tested for homogeneity of data by Bartlett test and data additives were tested by Tukey test. Then the Honest Significant Difference Test (BNJ) is performed at the 5\% level. The relationship between C-organic soil, soil pH, soil moisture content, and soil temperature with soil respiration was tested by correlation test. The results showed that humic acid or P fertilization did not affect soil respiration in all observations. There was no correlation between soil $\mathrm{pH}$, C-organic soil, soil moisture content, and soil temperature with soil respiration in all observations. T-student test of soil respiration in maize plantations at the time of observation of 7 HST was significantly different from 56 HST, 7 HST was significantly different from 99 HST, and 56 HST was significantly different from 99 HST.
\end{abstract}

Keywords: Humic acid, P fertilization, soil respiration.

\begin{abstract}
ABSTRAK
Ultisols adalah salah satu jenis tanah yang memiliki masalah kemasaman tanah, bahan organik dan ketersediaan P. Upaya untuk meningkatkan kualitas tanah Ultisols adalah dengan menerapkan penggunaan pupuk $P$ dengan bahan pembenah tanah. Penelitian bertujuan untuk mempelajari pengaruh asam humat dan pemupukan $P$ terhadap respirasi tanah. Penelitian ini dilaksanakan dari Desember 2018 sampai Mei 2019 di Kebun Percobaan Badan Pengkajian Teknologi Pertanian (BPTP) Natar, menggunakan Rancangan Acak Kelompok faktorial dengan dua faktor perlakuan. Faktor pertama yaitu tanpa asam humat (H0), asam humat $15 \mathrm{~kg}$ ha-1 (H1) dan asam humat $30 \mathrm{~kg}$ ha-1 (H2). Faktor kedua yaitu tanpa pupuk TSP (P0), pupuk TSP $100 \mathrm{~kg}$ ha-1 (P1), pupuk TSP $200 \mathrm{~kg}$ ha-1 (P2) dan pupuk TSP 300 kg ha-1 (P3). Data yang diperoleh diuji homogenitas ragamnya dengan uji
\end{abstract}


Bartlett dan aditivitas data diuji dengan uji Tukey. Selanjutnya dilakukan uji Beda Nyata Jujur (BNJ) pada taraf 5\%. Hubungan antara C-organik tanah, $\mathrm{pH}$ tanah, kadar air tanah, dan suhu tanah dengan respirasi tanah diuji dengan uji korelasi. Untuk melihat perbedaan antar waktu pengamatan dilakukan uji T-student. Hasil penelitian menunjukkan bahwa aplikasi asam humat atau pemupukan P tidak mempengaruhi respirasi tanah pada semua pengamatan. Tidak terdapat korelasi antara $\mathrm{pH}$ tanah, $\mathrm{C}$-organik tanah, kadar air tanah dan suhu tanah dengan respirasi tanah pada semua pengamatan. Uji T-student respirasi tanah di pertanaman jagung pada waktu pengamatan 7 HST berbeda nyata dengan 56 HST, 7 HST berbeda nyata dengan 99 HST, dan 56 HST berbeda nyata dengan 99 HST.

Kata kunci: Asam humat, Pemupukan P, Respirasi tanah.

\section{PENDAHULUAN}

Tanah merupakan lapisan permukaan bumi yang secara fisik berfungsi sebagai tempat tumbuh dan berkembangnya perakaran dan penopang tegak tumbuhnya tanaman serta penyuplai kebutuhan air dan udara. Secara biologis tanah berfungsi sebagai habitat biota (organisme) yang berperan aktif dalam menyediakan unsur hara bagi tanaman sehingga mampu menunjang produktivitas tanah untuk menghasilkan biomassa dan produksi baik tanaman pangan, obatobatan, industri perkebunan, maupun kehutanan (Hanafiah, 2007).

Upaya yang dapat dilakukan untuk meningkatkan produktivitas lahan adalah dengan menambahkan pupuk pada lahan pertanian. Menurut Rukmana (1997), pemberian pupuk urea, TSP dan $\mathrm{KCl}$ sebagai sumber $\mathrm{N}, \mathrm{P}$, dan $\mathrm{K}$ merupakan salah satu usaha untuk meningkatkan produksi tanaman. Selain itu, pemupukan yang efektif dan efisien sangat penting dilakukan terutama pada tanah-tanah marginal seperti tanah ultisols yang memiliki tingkat kesuburan rendah. Tanah ultisols mempunyai sebaran luas mencapai 45.794.000 ha atau sekitar 25\% dari total luas daratan Indonesia (Subagyo dkk., 2004), sehingga efisiensi pemupukan perlu ditingkatkan. Salah satunya yaitu dengan memperbaiki sifat tanah yang antara lain dengan menambahkan bahan pembenah tanah.

Pembenah tanah merupakan suatu bahan yang dapat digunakan untuk mempercepat pemulihan atau perbaikan kualitas tanah. Hasil penelitian Dariah dkk. (2010) menunjukkan bahwa perlakuan perbedaan formula pembenah tanah berpengaruh nyata terhadap aktivitas mikroorganisme tanah, seperti ditunjukkan oleh perbedaan nyata hasil pengukuran respirasi tanah.

Asam humat merupakan salah satu pembenah tanah yang digunakan dalam bidang pertanian karena dapat berpengaruh secara langsung maupun secara tidak langsung terhadap tanah. Pengaruh secara langsung yaitu dapat memperbaiki proses metabolisme di dalam tanaman, seperti dapat meningkatkan proses laju fotosintesis tanaman (Heil, 2005). Sedangkan pengaruh secara tidak langsung yaitu dapat memperbaiki sifat fisik, kimia dan biologi tanah terutama pada tanah yang berpasir atau tanah ultisols (Tan, 1993). Sehingga dengan penambahan asam humat ke dalam tanah diharapkan dapat meningkatkan mikroorganisme tanah yang menyebabkan kualitas tanah dan produktifitas tanaman juga akan meningkat. 
Respirasi tanah merupakan salah satu indikator dari aktivitas biologi tanah seperti mikroba, akar tanaman atau kehidupan lain yang ada di dalam tanah. Respirasi tanah adalah proses evolusi $\mathrm{CO}_{2}$ dari tanah ke atmosfer, terutama yang dihasilkan oleh aktivitas mikroorganisme tanah dan akar tanaman.

Jagung (Zea mays L) merupakan salah satu tanaman pangan penting di Indonesia karena bermanfaat sebagai sumber bahan pangan berkarbohidrat tinggi yang dapat digunakan sebagai sumber makanan pokok setelah padi. Pada penelitian ini, tanaman jagung dijadikan sebagai tanaman indikator dalam pemberian asam humat dan pemupukan $\mathrm{P}$ (Phosphate) yang akan diukur laju respirasi tanahnya. Penelitian ini bertujuan untuk mempelajari pengaruh aplikasi asam humat, pemupukan P, dan interaksi antara keduanya terhadap respirasi tanah pada pertanaman jagung (Zea mays L.) di tanah Utisols.

\section{BAHAN DAN METODE}

Penelitian dilakukan pada bulan Desember 2018 sampai dengan Mei 2019 di Kebun Percobaan Badan Pengkajian Teknologi Pertanian (BPTP) Natar dan analisis tanah dilakukan di Laboratorium Ilmu Tanah Fakultas Pertanian Universitas Lampung. Penelitian dilakukan dengan menggunakan Rancangan Acak Kelompok yang disusun secara faktorial dengan dua faktor perlakuan. Faktor pertama yaitu aplikasi asam humat yang dibagi menjadi 3 taraf yaitu tanpa aplikasi asam humat, asam humat $15 \mathrm{~kg} \mathrm{ha}^{-1}$ dan asam humat $30 \mathrm{~kg} \mathrm{ha}^{-1}$. Faktor kedua yaitu pemupukan P yang dibagi menjadi 4 taraf yaitu tanpa pupuk TSP, pupuk
TSP $100 \mathrm{~kg} \mathrm{ha}^{-1}$, pupuk TSP $200 \mathrm{~kg} \mathrm{ha}^{-1}$ dan pupuk TSP $300 \mathrm{~kg} \mathrm{ha}^{-1}$. Setiap perlakuan diulang sebanyak 3 kali sehingga diperoleh 36 satuan percobaan. Data yang diperoleh dilakukan uji homogenitas ragam dengan uji Bartlett dan aditifitas data diuji dengan uji Tukey. Jika asumsi terpenuhi maka akan dilakukan analisis ragam. Selanjutnya dilakukan uji Beda Nyata Jujur (BNJ) pada taraf 5\%. Untuk mengetahui hubungan antara C-organik tanah, $\mathrm{pH}$ tanah, kadar air tanah, dan suhu tanah dengan respirasi tanah maka dilakukan Uji korelasi. Untuk mengetahui perbedaan antar waktu pengamatan dilakukan uji T-student.

Variabel utama penelitian ini adalah laju Respirasi Tanah dengan Metode Verstreate yang dimodifikasi (Anas, 1989). Pengukuran respirasi tanah di lapang dilakukan kali yaitu pada saat fase vegetatif awal, vegetatifmaksimum, dan pada saat sebelum panen.

Langkah yang dilakukan yaitu botol film yang

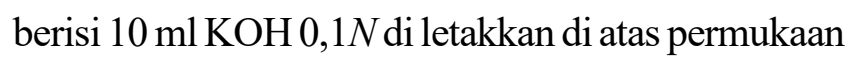
tanah dan ditutup dengan toples penyungkup. Pengukuran respirasi tanah ini dilakukan selama 2 jam. Langkah yang sama dilakukan untuk kontrol, dimana botol film diletakkan di atas permukaan tanah datar yang ditutup dengan plastik sehingga $\mathrm{KOH}$ tidak dapat menangkap $\mathrm{CO}_{2}$ yang keluar dari tanah. Jumlah $\mathrm{CO}_{2}$ dihitung dengan rumus:

$$
C-\mathrm{CO}_{2}=\frac{(a-b) \times t \times 12}{T \times \pi \times r^{2}}
$$

Keterangan:

$\mathrm{C}-\mathrm{CO}_{2}=\mathrm{mg} \mathrm{jam}^{-1} \mathrm{~m}^{-2}$

$\mathrm{a}=\mathrm{ml} \mathrm{HCl}$ sampel (setelah ditambahkan metyl orange)

$\mathrm{b}=\mathrm{ml} \mathrm{HCl}$ blanko (setelah ditambahkan metyl orange) 
$\mathrm{t}=\operatorname{normalitas}(N) \mathrm{HCl}$

$\mathrm{T}=$ waktu (jam)

$\mathrm{r}=$ jari-jari tabung toples $(\mathrm{m})$

$12=$ massa atom $\mathrm{C}$

Variabel pendukung diamati secara bersamaan dengan melakukan pengukuran respirasi tanah pada saat fase vegetatif awal, vegetatif maksimum dan sebelum panen. Variabel pendukung yang diamati pada penelitian ini adalah kadar air tanah, C-organik, Suhu tanah, dan $\mathrm{pH}$ tanah.

\section{HASIL DAN PEMBAHASAN}

\section{Pengaruh Aplikasi Asam Humat dan Pemupukan} P terhadap Respirasi Tanah pada Pertanaman Jagung (Zea mays L.).

Hasil penelitian (Tabel 1) menunjukkan bahwa perlakuan asam humat dan pemupukan $P$ serta interaksi antara keduanya tidak berpengaruh nyata terhadap respirasi tanah pada semua pengamatan yaitu 7 HST, 56 HST dan 99 HST. Belum adanya pengaruh aplikasi asam humat terhadap respirasi tanah diduga akibat aplikasi asam humat yang diterapkan dalam waktu singkat belum menciptakan kondisi lingkungan yang sesuai untuk pertumbuhan mikroorganisme tanah. Hal tersebut sesuai dengan hasil penelitian Baskoro (2010) bahwa waktu pemberian asam humatyang relatif singkat ( 5 bulan) belum mampu memperbaiki sifat fisik tanah.

Perlakuan pemupukan P pada keempat taraf dosis yaitu tanpa pupuk $\mathrm{P}\left(\mathrm{P}_{0}\right)$, Pupuk TSP $100 \mathrm{~kg} \mathrm{ha}^{-1}$ $\left(\mathrm{P}_{1}\right)$, pupuk TSP $200 \mathrm{~kg} \mathrm{ha}^{-1}\left(\mathrm{P}_{2}\right)$ dan pupuk TSP 300 $\mathrm{kg} \mathrm{ha}^{-1}\left(\mathrm{P}_{3}\right)$ pada lahan pertanian belum memberikan pengaruh yang nyata terhadap respirasi tanah. Belum berpengaruhnya perlakuan pemupukan $\mathrm{P}$ diduga karena pupuk P yang diaplikasikan terlebih dahulu meningkatkan pertumbuhan tanaman jagung.

Hasil penelitian(Tabel2) menunjukkan bahwa laju respirasi tanah dipengaruhi oleh waktu pengamatan selama pertumbuhan tanaman jagung. Laju respirasi tanah pada pengamatan 56 HST lebih tinggi dari pengamatan $7 \mathrm{HST}$, dan pada pengamatan $99 \mathrm{HST}$ lebih tinggi dari pengamatan 56 HST. Pada pengamatan 56 HST laju respirasi tanah meningkat diduga karena pada saat itu tanaman jagung sedang aktif tumbuh, sehingga perakaran tanaman jagung maksimal dalam mengeluarkan eksudat dan $\mathrm{CO}_{2}$. Eksudat yang dikeluarkan oleh perakaran tanaman jagung dapat digunakan sebagai sumber energi oleh mikroorganisme tanah. Karbondioksida yang di

Tabel 1. Ringkasan Analisis Ragam Pengaruh Aplikasi Asam Humat dan Pemupukan P Terhadap Respirasi Tanah pada Pengamatan 7 HST, 56 HST Dan 99 HST pada Pertanaman Jagung (Zea mays L.).

\begin{tabular}{cccc}
\hline Sumber Keragaman & \multicolumn{3}{c}{ F hitung dan signifikansi } \\
\hline H & $0,13^{\text {tn }}$ & $0,32^{\text {tn }}$ & $0,18^{\text {tn }}$ \\
P & $0,23^{\text {tn }}$ & $0,81^{\text {tn }}$ & $0,12^{\text {tn }}$ \\
X P & $0,59^{\text {tn }}$ & $2,05^{\text {tn }}$ & $0,74^{\text {tn }}$ \\
\hline
\end{tabular}

Keterangan : $\mathrm{H}=$ asam humat; $\mathrm{P}=$ pemupukan $\mathrm{P} ; \mathrm{HxP}=$ interaksi asam humat dan pupuk $\mathrm{P}$; $\mathrm{tn}=$ tidak nyata pada taraf $5 \%$. 
Tabel 2. Ringkasan Uji T-student Respirasi Tanah di Pertanaman Jagung pada Waktu Pengamatan yang berbeda.

\begin{tabular}{cc}
\hline & $\begin{array}{c}\text { Respirasi Tanah } \\
\end{array}$ \\
\hline Waktu Pengamatan & T hitung \\
\hline 7 HST VS 56 HST & $37,79^{* *}$ \\
7 HST VS 99 HST & $46,99^{* *}$ \\
56 HST VS 99 HST & $9,03^{* *}$ \\
\hline
\end{tabular}

Keterangan : HST $=$ hari setelah tanam; ${ }^{* *}=$ sangat berbeda nyata pada taraf $1 \%$.

Tabel 3. Ringkasan Analisis Ragam Pengaruh Aplikasi Asam Humat dan Pemupukan P terhadap Suhu Tanah pada Pengamatan 7 HST, 56 HST dan 99 HST di Pertanaman Jagung (Zea mays L.).

\begin{tabular}{cccc}
\hline Sumber Keragaman & \multicolumn{3}{c}{ F hitung dan signifikansi } \\
\hline H & $1,11^{\text {tn }}$ & $0,46^{\text {tn }}$ & $0,61^{\text {tn }}$ \\
P & $0,45^{\text {tn }}$ & $0,42^{\text {tn }}$ & $1,45^{\text {tn }}$ \\
H x P & $1,37^{\text {tn }}$ & $0,20^{\text {tn }}$ & $0,93^{\text {tn }}$ \\
\hline
\end{tabular}

Keterangan : $\mathrm{tn}=$ tidak berbeda nyata pada taraf $5 \% ; \mathrm{H}=$ asam humat; $\mathrm{P}=$ pemupukan $\mathrm{P} ;$ dan $\mathrm{H} \times \mathrm{P}=$ interaksi antara asam humat dan pemupukan $P$.

tangkap oleh $\mathrm{KOH}$ tidak hanya dari mikroorganisme tanah, tetapi juga oleh perakaran tanaman melalui proses respirasi akar. Laju respirasi meningkat pada pengamatan 99 HST diduga karena banyaknya gulma yang tumbuh disekitar pertanaman jagung, hal ini mengakibatkan $\mathrm{KOH}$ tidak hanya mengikat $\mathrm{CO}_{2}$ dari mikroorganisme tanah dan tanaman jagung tetapi juga dari gulma yang tumbuh disekitar pertanaman jagung.

\section{Pengaruh Aplikasi Asam Humat dan} Pemupukan P terhadap Kadar Air, C-Organik, Suhu dan pH Tanah pada Pertanaman Jagung

\section{(Zea mays L.).}

Hasil analisis suhu tanah (Tabel 3) menunjukkan bahwa perlakuan aplikasi asam humat dan pemupukan $\mathrm{P}$ tidak berpengaruh nyata terhadap suhu tanah. Hasil pengukuran suhu tanah tertinggi yaitu pada pengamatan $7 \mathrm{HST}$ berkisar antara $34,55^{\circ} \mathrm{C}-$ $36,92^{\circ} \mathrm{C}$. Pada pengamatan $7 \mathrm{HST}$, tanaman jagung sedang masa vegetatifawal sehingga kanopi tanaman jagung belum menutupi permukaan tanah, sinar matahari akan langsung mengenai permukaan tanah, sehingga suhu tanah tinggi. Pada pengamatan 56 HST suhu tanah berkisar antara $26,37^{\circ} \mathrm{C}-29,10{ }^{\circ} \mathrm{C}$, dan 99 HST suhu tanah berkisar antara $25,92^{\circ} \mathrm{C}-32,83^{\circ} \mathrm{C}($ Tabel 3).

Hasil analisis kadar air tanah pada pengamatan 7 HST berkisar antara 18,28\% - 20,92\%, 56 HST berkisar antara $31,99 \%$ - 36,04\%, serta pada pengamatan 99 HST berkisar antara 31,85\% $35,57 \%$ (Tabel 4). Kadar air tanah sangat berperan terhadap proses yang terjadi di dalam tanah, khususnya yang berkaitan dengan aktivitas mikroorganisme tanah. Mikroorganisme tanah merupakan tenaga penggerak berlangsungnya proses dekomposisi bahan organik yang mempengaruhi laju respirasi tanah (Azizah dkk., 2007). 
Tabel 4. Ringkasan Analisis Ragam Pengaruh Aplikasi Asam Humat dan Pemupukan P terhadap Kadar Air Tanah pada Pengamatan 7 HST, 56 HST dan 99 HST di Pertanaman Jagung (Zea mays L.).

\begin{tabular}{|c|c|c|c|}
\hline Sumber Keragaman & & dan sig & \\
\hline $\mathrm{H}$ & $0,58^{\mathrm{tn}}$ & $5,26^{*}$ & $0,83^{\text {tn }}$ \\
\hline $\mathrm{P}$ & $0,40^{\text {tn }}$ & $2,24^{\mathrm{tn}}$ & $0,33^{\text {tn }}$ \\
\hline $\mathrm{H} \times \mathrm{P}$ & $0,63^{\text {tn }}$ & $2,05^{\mathrm{tn}}$ & $1,03^{\text {tn }}$ \\
\hline
\end{tabular}

Tabel 5. Pengaruh Aplikasi Asam Humat terhadap Kadar Air Tanah (\%) pada Pertanaman Jagung (Zea mays L.) Pengamatan 56 HST.

\begin{tabular}{cc}
\hline Perlakuan Asam Humat & Kadar Air Tanah \\
\hline & $\ldots \ldots \ldots(\%) \ldots \ldots \ldots$ \\
$\mathrm{H}_{0}$ & $34,95(\mathrm{a})$ \\
$\mathrm{H}_{1}$ & $33,12(\mathrm{~b})$ \\
$\mathrm{H}_{2}$ & $33,94(\mathrm{ab})$ \\
\hline
\end{tabular}

BNJ 5\% 1,55

Keterangan : $\mathrm{H}_{0}=$ tanpa aplikasi asam humat; $\mathrm{H}_{1}=$ aplikasi asam humat $5 \mathrm{~kg} \mathrm{ha}^{-1} ; \mathrm{H}_{2}=$ aplikasi asam humat $10 \mathrm{~kg}$ ha-1 $;$ nilai tengah yang diikuti oleh huruf yang sama tidak berbeda berdasarkan uji BNJ pada taraf $5 \%$.

Tabel 6. Ringkasan Analisis Ragam Pengaruh Aplikasi Asam Humat dan Pemupukan P terhadap pH Tanah pada Pengamatan 7 HST, 56 HST dan 99 HST di Pertanaman Jagung (Zea mays L.).

\begin{tabular}{cccc}
\hline Sumber Keragaman & \multicolumn{3}{c}{ F hitung dan signifikansi } \\
\hline H & $0,75^{\text {tn }}$ & $1,77^{\text {tn }}$ & $0,50^{\text {tn }}$ \\
P & $0,62^{\text {tn }}$ & $2,63^{\text {tn }}$ & $3,70^{*}$ \\
H x P & $2,18^{\text {tn }}$ & $1,70^{\text {tn }}$ & $0,89^{\text {tn }}$ \\
\hline
\end{tabular}

Keterangan : $\operatorname{tn}=$ tidak berbeda nyata pada taraf $5 \% ; *$ = berbeda nyata pada taraf $5 \% ; \mathrm{H}=$ asam humat; $\mathrm{P}=$ pemupukan $\mathrm{P} ;$ dan $\mathrm{H} \times \mathrm{P}=$ interaksi asam humat dan pemupukan $\mathrm{P}$.

Hasil analisis ragam (Tabel 5) menunjukkan bahwa aplikasi asam humat berpengaruh nyata terhadap kadar air tanah pada pengamatan 56 HST. Hal tersebut diduga karena pada saat pengamatan 56 HST, tanaman jagung sudah memasuki masa vegetatif maksimum. Pada fase tersebut kadar air tanah tinggi, hal ini diduga karena kanopi tanaman jagung sudah menutupi permukaan tanah sehingga sinar matahari yang datang tidak langsung mengenai permukaan tanah.
Hasil pengukuran $\mathrm{pH}$ tanah pada pengamatan 7 HST berkisar antara 4,96-5,45, 56 HST berkisar antara 4,54-4,97, dan pengamatan 99 HST berkisar antara 4,91 - 5,49 (Tabel 6). Hasil analisis ragam menunjukkan bahwa perlakuan pemupukan $\mathrm{P}$ berpengaruh nyata terhadap $\mathrm{pH}$ tanah pada pengamatan 99 HST. Perlakuan pemupukan P pada taraf dosis $200 \mathrm{~kg} \mathrm{ha}^{-1}\left(\mathrm{P}_{2}\right)$ menghasilkan $\mathrm{pH}$ tanah lebih tinggi dibandingkan dengan $\mathrm{P}_{0}, \mathrm{P}_{1}$ dan $\mathrm{P}_{3}$ (Tabel 7). 
Tabel 7. PengaruhAplikasi Pemupukan P terhadap pH Tanah pada Pertanaman Jagung (Zea mays L.) Pengamatan 99 HST.

\begin{tabular}{cc}
\hline Perlakuan Pemupukan P & $\mathrm{pH}$ Tanah \\
\hline Tanpa aplikasi pupuk TSP $\left(\mathrm{P}_{0}\right)$ & $5,25(\mathrm{ab})$ \\
Pupuk TSP $100 \mathrm{~kg} \mathrm{ha}^{-1}\left(\mathrm{P}_{1}\right)$ & $5,06(\mathrm{ab})$ \\
Pupuk TSP 200 kg ha- $\left(\mathrm{P}_{2}\right)$ & $5,37(\mathrm{a})$ \\
Pupuk TSP 300 kg ha- $\left(\mathrm{P}_{3}\right)$ & $4,98(\mathrm{~b})$ \\
\hline BNJ 5\% & 0,36 \\
\hline
\end{tabular}

Keterangan : nilai tengah yang diikuti oleh huruf yang sama tidak berbeda nyata berdasarkan uji BNJ pada taraf 5\%.

Tabel 8. Ringkasan Analisis Ragam Pengaruh Aplikasi Asam Humat dan Pemupukan P terhadap C-organik Tanah (\%) pada Pengamatan 7 HST, 56 HST dan 99 HST di Pertanaman Jagung (Zea mays L.).

\begin{tabular}{cccc}
\hline Sumber Keragaman & \multicolumn{3}{c}{ F hitung dan signifikansi } \\
\hline H & $0,33^{\text {tn }}$ & $0,32^{\text {tn }}$ & $0,16^{\text {tn }}$ \\
P & $0,64^{\text {tn }}$ & $1,31^{\text {tn }}$ & $1,31^{\text {tn }}$ \\
H x P & $0,98^{\text {tn }}$ & $0,25^{\text {tn }}$ & $0,43^{\text {tn }}$ \\
\hline
\end{tabular}

Keterangan : $\mathrm{tn}=$ tidak berbeda nyata pada taraf $5 \% ; \mathrm{H}=$ asam humat; $\mathrm{P}=$ pemupukan $\mathrm{P} ;$ dan $\mathrm{H} \times \mathrm{P}=$ interaksi antara asam humat dan pemupukan $P$.

Walaupun secara statistika demikian, $\mathrm{pH}$ tanah pada keempat tarafdosis pemupukan $\mathrm{P}$ tersebut masih dalam kriteria yang sama yaitu agak masam $(4,5-6,5)$ (Departemen Pertanian, 1983 dalam Suhariyono dan Menry, 2005) sehingga belum berpengaruh terhadap aktivitas mikroorganisme tanah. $\mathrm{pH}$ tanah mempunyai peran penting bagi perkembangan mikroorganismeyang ada didalam tanah. Hanafiah (2005) menyatakan bahwa fungi lebih dominan pada $\mathrm{pH}$ rendah dibandingkan dengan bakteri dan aktinomisetes, begitu pula sebaliknya. Namun secara umum perkembangan dan aktivitas mikrobia yang ada di dalam tanah optimum pada $\mathrm{pH}$ 6,5 - 7 .

Hasil analisis C-organik tanah pada pengamatan 7 HST berkisar antara 1,00\% - 1,28\%, 56 HST berkisar antara $1,18 \%-1,47 \%$, serta pada pengamatan 99 HST berkisar antara 1,20\%-1,44\%
(Tabel 8). Kandungan C-organik tanah tersebut termasuk dalam kriteria C-organik yang rendah dengan persentase bahan organik $<2 \%$ (Balai Penelitian Tanah, 2009). Kandungan C-organik tanah yang rendah akan mempengaruhi aktivitas mikroorganisme tanah karena C-organik tanah merupakan sumber energi bagi mikroorganisme tanah dalam melakukan aktivitas hidupnya. Hal ini karena jenis tanah tersebut termasuk ke dalamjenis tanah Ultisols yang mempunyai kandungan bahan organik rendah (Darmawijaya, 1990).

\section{Korelasi antara C-organik, Kadar Air,} Suhu, dan pH Tanah dengan Respirasi Tanah.

Berdasarkan hasil uji korelasi pada pengamatan 7 HST, 56 HST, dan 99 HST menunjukkan bahwa perlakuan aplikasi asam humat dan pemupukan $\mathrm{P}$ tidak menunjukkan korelasi yang 
Tabel 9. Uji Korelasi antara C-organik Tanah, Kadar Air Tanah, Suhu Tanah, dan pH Tanah dengan Respirasi Tanah.

\begin{tabular}{cccc}
\hline \multirow{2}{*}{ Pengamatan } & \multicolumn{3}{c}{ Koefisien Korelasi (r) } \\
\cline { 2 - 4 } & 7 HST & Respirasi Tanah \\
\cline { 2 - 4 } & $0,07^{\text {tn }}$ & $0,35^{\text {tn }}$ & 09 HST \\
\hline C-organik $(\%)$ & $0,14^{\text {tn }}$ & $0,04^{\text {tn }}$ & $0,08^{\text {tn }}$ \\
Kadar Air Tanah $(\%)$ & $0,14^{\text {tn }}$ & $0,14^{\text {tn }}$ & $0,05^{\text {tn }}$ \\
Suhu Tanah $\left({ }^{\circ} \mathrm{C}\right)$ & $0,10^{\text {tn }}$ & $0,02^{\text {tn }}$ & $0,07^{\text {tn }}$ \\
pH Tanah &
\end{tabular}

Keterangan : $\mathrm{HST}=$ hari setelah tanam; $\mathrm{tn}=$ tidak nyata; dan *= berpengaruh nyata pada taraf $5 \%$.

nyata antara suhu tanah, kadar air tanah, C-organik tanah dan $\mathrm{pH}$ tanah dengan respirasi tanah (Tabel 9). Hal ini dapat diartikan bahwa pada perlakuan asam humat dan pemupukan $\mathrm{P}$, tinggi atau rendahnya laju respirasi tanah tidak tergantung pada suhu tanah, kadar air tanah, C-organik tanah, dan $\mathrm{pH}$ tanah. Korelasi yang tidak nyata antara beberapa taraf dosis asam humat dan pemupukan $P$ dengan respirasi tanah diduga karena jangka waktu penelitian yang singkat sehingga belum terciptanya kondisi yang sesuai untuk pertumbuhan mikroorganisme tanah.

\section{KESIMPULAN}

Aplikasi asam humat tidak mempengaruhi respirasi tanah pada semua pengamatan pada pertanaman jagung di tanah Ultisols. Pemupukan P tidak mempengaruhi respirasi tanah pada semua pengamatan pada pertanaman jagung di tanah Ultisols. Tidak terdapat interaksi antara aplikasi asam humat dan pemupukan $\mathrm{P}$ terhadap respirasi tanah pada semua pengamatan pada pertanaman jagung di tanah Ultisols. Uji T-student respirasi tanah di pertanaman jagung pada waktu pengamatan 7 HST berbeda nyata dengan 56
HST, 7 HST berbeda nyata dengan 99 HST, dan 56 HST berbeda nyata dengan 99 HST.

\section{UCAPAN TERIMAKASIH}

Terimakasih kepada bapak dan ibu dosen Jurusan Agroteknologi Fakultas Pertanian atas bimbingan, saran, nasihat-nasihat, serta kesabaran dalam memberikan bimbingannya kepada penulis dan semua pihak yang telah membantu terselesaikannya skripsi ini.

\section{DAFTAR PUSTAKA}

Anas, I. 1989. Biologi Tanah dalam Praktek. Departemen Pendidikan dan Kebudayaan Direktorat Jenderal Pendidikan Tinggi Pusat Antar Universitas Bioteknologi. Institut Pertanian Bogor. Bogor. 161 hlm.

Azizah, R., Subagyo, dan E. Rosanti. 2007. Pengaruh kadar air terhadap laju respirasi tanah tambak pada penggunaan katul padi sebagai priming agent. Jurnal Ilmu Kelautan, 12(2): 67-72.

Balai Penelitian Tanah. 2009. Analisis Kimia Tanah, Tanaman, Air, dan Pupuk. Petunjuk Teknis Edisi 2. Balai Penelitian Tanah. Bogor. $246 \mathrm{hlm}$. 
Baskoro, D.P.T. 2010. Pengaruh pemberian bahan humat dan kompos sisa tanaman terhadap sifat fisik tanah dan produksi ubi kayu. Jurnal Tanah dan Lingkungan. 12(1) :9-14.

Dariah, A., Sutono. dan N. L. Nurida. 2010. Penggunaan Pembenah Tanah Organik dan Mineral untuk Perbaikan Kualitas Tanah Tyipic Kanhapludults Tamanbogo, Lampung. Jurnal Tanah dan Iklim 31: 1-9.

Darmawijaya, M. I. 1990. Klasifikasi Tanah. Gadjah Mada University Press. Yogyakarta. 411 hlm.

Hanafiah, K. A. 2005. Dasar-Dasar Ilmu Tanah. PT Raja Grafindo Persada. Jakarta. $360 \mathrm{hlm}$.

Hanafiah, K. A. 2007. Dasar-Dasar Ilmu Tanah. PT Raja Grafindo Persada. Jakarta. $165 \mathrm{hlm}$.

Heil, C. A. 2005. Influence of Humic, Fulvic and Hydrophilic Acids on the Growth, Photosynthesis and Respiration of the Dinoflagelatte Prorocentrum Minimum (Pavillard) Schiller. Harmful Algae 4: 603-618.

Kuzyakov, Y. 2006. Sources of $\mathrm{CO}_{2}$ efflux from soil and review of partitioning methods. Soil Biology and Biochemistry, 38: 425-448.
Rukmana, R. 1997. Usaha Tani Jagung. Kanisius. Yogyakarta. $84 \mathrm{hlm}$.

Sofatin, S., Fitriatin B. N., dan Machfud Y. 2016. Pengaruh kombinasi pupuk NPK dan pupuk hayati terhadap populasi total mikroba tanah dan hasil jagung manis (Zea mays L. saccharata) pada inceptisols jatinagor. Soilrens. 14(2) :33-37.

Subagyo, H., N. Suharta., dan A. B. Siswanto. 2004. Tanah-tanah Pertanian di Indonesia. Dalam Prasetya, B. H., Suriadikarta, D. A. 2006. Pengelolaan Tanah Ultisol untuk Pengembangan Pertanian Lahan Kering di Indonesia. Balai Penelitian Tanah. Bogor. Hal: 21-26.

Suhariyono, G. dan Y. Menry. 2005. Analisis karakteristik unsur-unsur dalam tanah di berbagai lokasi dengan menggunakan XRF. Prosiding PPI-PDIPTN. Yogyakarta, 12 Juli 2005. Hal. 197-206.

Tan, K. H. 1993. Dasar-dasar Kimia Tanah. diterjemahkan oleh Didiek Hadjar Geonadi. Marcel Gajah Mada University Press. 295 hlm. 